\title{
The background of the Norwegian Mother and Child Cohort Study
}

\author{
Lorentz M. Irgens \\ Professor of Preventive Medicine, University of Bergen, former Director of the Medical Birth Registry of Norway
}

This is an open access article distributed under the Creative Commons Attribution Licence, which permits unrestricted use, distribution, and reproduction in any medium, provided the original work is properly cited.

The background why the Norwegian Mother and Child Cohort Study (MoBa) was conceived and its aims are complex and multifactorial, and the replies you get if you ask for clarification of these issues will depend on whom you ask. As an actor in the conception and initiation of the study, I have been asked to account for my personal view how it all started.

The MoBa has since its initiation been closely related to the Medical Birth Registry of Norway (MBRN) comprising detailed medical data on all births after 16 weeks of gestation in the country. Established in the wake of the thalidomide catastrophe, in 1970 by Tor Bjerkedal, at that time professor of preventive medicine and head of Institute for hygiene and social medicine, University of Bergen, the MBRN came to represent the first national medical birth registry worldwide. Otherwise, perinatal epidemiological efforts had been based on ad hoc or more permanent case control studies. An ambitious cohort design, comprising all births in the country identified by the national identification number, opened up possibilities for epidemiological research never envisaged before. The aims were to monitor and shed light on causes of adverse pregnancy outcomes as well as to study associations between various pregnancy outcomes and subsequent health problems.

Eventually, the MBRN came to collect substantial amounts of data, and in the 1980s, when the number of births reached a level at which more comprehensive epidemiological analyses became feasible, the lack of certain analytical variables was evident. First, data on a number of potential risk factors for various adverse outcomes of pregnancy were not registered. Second, in spite of possibilities of linkage with other registers, data on important health problems after birth were not at hand. As head of the MBRN at that time, I felt the responsibility for filling these gaps in items of personal data.

With monitoring of birth defects as one of its two main aims, MBRN became, in 1974, a founding member of International Clearinghouse for Birth Defects Monitoring Systems (Clearinghouse). In order to improve its worldwide monitoring and research, Clearinghouse established, in 1989, its International Centre for Birth Defects (ICBD) at MBRN in Bergen under the auspices of the Norwegian Government. The initiative represented an ambitious cooperation between the MBRN and Clearinghouse as well as the Norwegian Institute of Public Health. The aims were worldwide monitoring of birth defects and etiologic epidemiolo- gical research. To meet these aims, a comprehensive infrastructure was established. However, in 1991, Clearinghouse decided for various reasons, at its Annual Meeting in Australia, to move ICBD to Rome.

This was a heavy and unexpected blow to the MBRN in Bergen and admittedly to me as well. However, I decided to deal with the problems in what I thought was a brave and constructive way. In part I gave a speech at the table in Canberra in which I, to some participants' surprise, cited (prophetically!) the Danish poet Piet Hein: "The noble art of losing face/ may one day save the human race/ and turn into eternal merit/ what weaker minds would call disgrace". (If not quite "eternal" MoBa has turned out to be a true scientific merit).

In part, and much more important, I had a conversation onboard the plane back to Norway with the director general of the Norwegian Institute of Public Health, Dr. Bodolf Hareide, who had attended the meeting in Australia as chair of the ICBD Board of Directors. The following situation was on our agenda.

The unit in Bergen was left with a strong analytical infrastructure without any mission. However, at the time, the MBRN had been confronted with important challenges in epidemiological monitoring and research related to increasing public concern with environmental pollution. Some years earlier, in 1986, the Chernobyl power plant disaster had raised questions whether the radioactive fallout might cause adverse pregnancy outcomes in Norway (1). At the same time, a potential cluster of birth defects in the Royal Norwegian Navy (2) attracted sustained attention in Norwegian media and called for initiatives among politicians aiming at clarification of this and similar clusters. Such incidents demonstrated the lack of data on exposure and follow up in our perinatal epidemiological research.

Throughout the 1980s, the MBRN, in cooperation with the Directorate of Health and the Norwegian Institute of Public Health, had been involved in a radical revision of the registration of data related to pregnancy and delivery, including the pregnancy record and the MBRN notification form. The pregnancy record already included a number of items of data representing potential risk factors important in epidemiological studies, however routinely not forwarded to the MBRN. MBRN had conducted a feasibility study in a Norwegian county (Nordland), and it was evident that the collection, registration and analysis of such data would be of great value, but needed considerable resources in terms of man power. The need of syste- 
matic registration of this type of data during pregnancy as well as data on follow up of the children was the context in which the MoBa study was conceived.

Hareide realized the scientific potentials of such a dataset. Furthermore, he consented to keep the personnel that had been affiliated with ICDB in Bergen in order to utilize their qualifications in the new project. Already in the 1991 Annual Report of the MBRN, the project was referred to as the "cohort project", and its ambitious aim was to include all women in the country having their first pregnancy consultation during one calendar year (3).

This was the slender beginning of the Norwegian MoBa Study, which during the 1990s had its protocol further developed into its recent ambitious scheme. This decade also saw the struggle for financial and political support as well as professional controversies with colleagues claiming that risk oriented research was unethical. In the resolution of these challenges Hareide became instrumental.

\section{REFERENCES}

1. Irgens LM, Lie RT, Ulstein M, Skeie Jensen T, Skjærven R, Sivertsen E, Reitan JB, Strand P, Strand T, Skjeldestad FE. Pregnancy outcome in Norway after Chernobyl. Biomed Pharmacoter 1991; (45): $233-241$.

2. Kristensen P, Jacobsen K, Skyberg K. Birth defects among children of fathers with service onboard HNoMS Kvikk (In Norwegian). STAMI Report No. 3/2000. Oslo, Statens arbeidsmiljøinstitutt, 2000.

3. Annual Report 1991, Medical Birth Registry of Norway (summary in English). Bergen, 1993. 